\title{
Effectiveness of Occupational Therapy Intervention in Young Onset Parkinson's Disease- A Case Report
}

\author{
Baldeep Kaur Sehra ${ }^{1}$, Preetee Gokhale ${ }^{2}$ \\ ${ }^{1}$ Master of Occupational Therapy 3rd year, ${ }^{2}$ Assistant Professor, \\ Occupational Therapy School and Centre, Seth G.S. Medical College and KEM Hospital, Mumbai
}

Corresponding Author: Baldeep Kaur Sehra

\begin{abstract}
This is a case study of 32 year old Mrs. M, a case of Young Onset Parkinson's Disease (YOPD) with hypothyroidism. With informed consent, Mrs. M was selected for the case report because Young Onset Parkinson's Disease is a rare diagnosis. She was assessed using MDSUPDRS pre- and post-intervention .She was provided Occupational Therapy intervention using the Person-Environment-Occupation Model for a period of three months and has shown significant improvement in UPDRS scores.
\end{abstract}

Her primary diagnosis is Young Onset Parkinson's Disease, secondary diagnosis being hypothyroidism. The patient, being in her early 30 s, many of her life roles were altered.

The patient's main concerns are that she has difficulty in performing her basic and instrumental ADLs and difficulty in caring for her loved ones.

Mrs. M was treated on weekly basis for an intervention period of three months using the Person Environment Occupation Model and assessed using the Unified Parkinson's Disease Rating Scale; pre and post treatment. She was in stage 3 of Hoehn and Yahr scale of classification of Parkinson's Disease.

Scores were assessed on Unified Parkinson's Disease Rating Scale, pre and post three months of intervention; showed improvement in non motor and motor aspects of experiences of daily living, motor examination and motor complications.

Component scores were decreased dramatically especially in the areas of anxious mood, fatigue, tremors, posture and bradykinesia which revealed that functional levels improved following intervention.
Keywords: Young Onset Parkinson's Disease, Unified Parkinson's Disease Rating Scale, Person Environment Occupation (PEO) based Occupational Therapy Intervention, case report

\section{INTRODUCTION}

Parkinson's Disease (PD) is a neurodegenerative, irreversible condition ${ }^{1}$. It is an illness that affects nerve cells in the brain that control movement. These cells are present in the substantia nigra of the midbrain. In people with PD, 70-80 \% of these cells degenerate and are lost gradually. These cells produce dopamine, a neurotransmitter which controls smooth movements of the body. Parkinson's Disease is progressive, which means symptoms appear gradually and slowly get worse ${ }^{1}$.

Parkinson's Disease is characterised by following symptoms: tremors, muscle rigidity and slowness of movement (bradykinesia). These are called motor symptoms. Gradually, as the dopamine producing cells degenerate, the symptoms of PD increases till the point it becomes very difficult for the person to carry out their activities of daily living(ADLs), to move about, results in frequent falls due to freezing episodes, reduced community mobility due to above mentioned motor symptoms. Many people with PD also experience other problems not related to movement, such as pain, anxiety and depression. These are called non-motor symptoms ${ }^{1}$. 
Typically, most people who get PD are over 60 years of age but Young Onset Parkinson's Disease occurs in people younger than 40 years of age ${ }^{2}$.

Mrs. M was selected for the case study because YOPD is a rare diagnosis ${ }^{2}$. She is a young female in her early 30 s and PD has brought about many changes in her life thus altering her life roles as a daughter, a daughter-in-law, a wife and a mother. Also the impact of PD is lifelong as the lifespan is not affected but the symptoms goes on increasing gradually thus confining the patient's movements and activities ${ }^{1}$.

\section{Patient information}

A 32 year old female patient, Mrs. $\mathrm{M}$, educated till $9^{\text {th }}$ standard, right handed was referred to Occupational Therapy department from Neurology OPD in a tertiary care centre in Mumbai for rehabilitation on $24^{\text {th }}$ July, 2020. On interviewing, she revealed complaints of tremulousness of hands on doing work like stirring the pot and leg tremors while walking. She complained of stiffness of whole body, of feeling loss of balance while walking, difficulty in eating using her hands ${ }^{1}$. She also complained of difficulty in taking care of her 8 year old daughter. She also complained of easy fatiguability on doing excessive work or walking and slowness while doing any activity. She also expressed about decreased intensity of speech and easy fatiguability on speaking too much. She was also anxious about her daughter's schooling and future concerns.

She first noticed slowness of movements and weakness of her right leg while walking (it was first noticed by her husband) around 2 years back in January 2019. Patient consulted a private practitioner and was referred to a multi speciality hospital in Mumbai where she was diagnosed as a case of hypothyroidism (she was prescribed tablet Thyronorm). She could not follow up properly due to some marital disharmony and familial issues. Later in January 2020, she was referred to a tertiary care centre in Mumbai with complaints of tremulousness of hands and legs and the above mentioned complaints where she was diagnosed as a case of Young Onset Parkinson's Disease on the basis of clinical presentation. She was prescribed tablets Pramipexole and Pacitane which has helped in reducing her symptoms to some extent.

\section{Clinical findings}

On neurological examination, it was found that patient had cogwheel rigidity of limbs, truncal rigidity, bradykinesia, tremors and weakness of bilateral upper and lower limbs. Her static and dynamic balance was affected along with postural instabilities. She had characteristic Parkinsonian gait. She was not able to express non-verbally through facial expressions due to masked face. She was in stage 3 of Hoehn and Yahr scale for classification of PD which suggested bilateral involvement with postural instability but independent.

\section{Timeline}

Patient is symptomatic since 2019, actively seeking Occupational Therapy treatment since August 2020

\section{Diagnostic assessment}

MRI Brain in January 2019 did not yield any findings. But she was diagnosed with hypothyroidism at the same time. UPDRS scores are shown in the Table-1 $\mathbf{1}^{3 .}$

\section{Therapeutic Intervention}

Mrs. M was evaluated and treated using Occupational Therapy interventions based on the Person-EnvironmentOccupation Model and rehabilitative frame of reference ${ }^{4}$.

\section{Person}

Mrs. M was able to perform all her activities of daily living like bathing, dressing, eating but with difficulty sometimes requiring mild assistance from family members. She had difficulty in her home management activities like cooking and gets fatigued easily. Also she could not adequately care for her family members. 
She was forced to leave her job as a housekeeping staff in a shop as she was not able to fulfil the demands of the job. Patient expressed her inability to participate in leisure activity due to illness. She also expressed about her inability to participate in meaningful social relationships with spouse and in-laws. She was not able to give adequate time to various activities of daily living as she took longer time for each task.

On neurological examination, it was found that patient had cogwheel rigidity of limbs, truncal rigidity, tremors and weakness of bilateral upper and lower limbs. Her static and dynamic balance were affected along with postural deviations. She had characteristic Parkinsonian gait. She was not able to express non-verbally through facial expressions due to masked face $^{5}$. She was in stage 3 of Hoehn and Yahr scale for classification of PD which suggested bilateral involvement with postural instability but independent

\section{Environment}

She is currently in early adulthood stage of her life with a progressive disability. She lives in a 1 room kitchen apartment in a residential area in Mumbai with her maternal relatives. She doesn't stay with her in-laws due to differences of opinion. Patient does not participate in social events as she feels ashamed of her condition $^{6 .}$

\section{Occupation}

She was not able to fulfil her life roles as a wife and mother which she could do earlier. Also she was not able to perform HR job as a housekeeping staff.

$\mathrm{Pt}$ was assessed on Unified Parkinson's Disease Rating Scale pre- and post- 3 months of Occupational Therapy intervention after taking a formal written consent ${ }^{3}$.

Some of the subcomponents of the UPDRS showing significant changes pre and post intervention. [See Table-1]

The following frames of references Frame of Reference was used in the intervention

Table-1
\begin{tabular}{|l|c|c|}
\hline \multicolumn{1}{|c|}{ Sub components } & $\begin{array}{c}\text { Pre } \\
\text { intervention }\end{array}$ & $\begin{array}{c}\text { Post } \\
\text { intervention }\end{array}$ \\
\hline Facial Expression & 2 & 1 \\
\hline Finger tapping- Right hand & 2 & 1 \\
\hline Finger tapping- Left hand & 2 & 1 \\
\hline Hand movements- Right & 1 & 0 \\
\hline Hand movements- Right & 3 & 2 \\
\hline Hand movements- Left & 2 & 1 \\
\hline Toe tapping-Right & 3 & 2 \\
\hline Toe tapping-Left & 2 & 1 \\
\hline Leg agility- Right & 1 & 0 \\
\hline Leg agility- Left & 1 & 0 \\
\hline $\begin{array}{l}\text { Global spontaneity of } \\
\text { movement }\end{array}$ & 2 & 1 \\
\hline Postural stability & 2 & 1 \\
\hline Tremors & 3 & 1 \\
\hline
\end{tabular}

\section{Rehabilitative Frame of Reference}

Mrs. M was treated as a part of the rehabilitation team. She was taught various adaptations, compensatory strategies and environmental modifications. As she gets fatigued easily, energy conservation and work simplification strategies were taught to her like using small pots and pans, encouraging bilateral hand use to facilitate performance, taking rest periods in between two tasks, sitting and doing the kitchen work, planning, collecting and assembling all the things required for cooking at one time so as to avoid going to and fro again. She was made to increase and maintain her competence in activities and to achieve mastery over her environment by teaching her various adaptive strategies, for eg- using a spoon while feeding, using smaller pans ${ }^{7}$. She was also encouraged to use creative media to keep herself occupied.

All the exercises were combined with a rhythmic music and encouraged to do in front of a full length mirror so that she gets visual feedback. She was started with flexibility and strengthening exercises of upper limbs, lower limbs, trunk and neck [Illustration-1]. Overhead arm movements and trunk rotations were encouraged. Static, dynamic balance and her gait were worked upon [Illustration-2 and 3],8,9,10.

Smania $\mathrm{N}$ et al. in their randomized controlled trial "Effect of Balance Training on Postural Instability in Patients With Idiopathic Parkinson's Disease" concluded that balance training in patients suffering from PD can improve performance in highly 
Baldeep Kaur Sehra et.al. Effectiveness of occupational therapy intervention in young onset Parkinson's Disease- a case report

relevant outcomes related to better postural control.

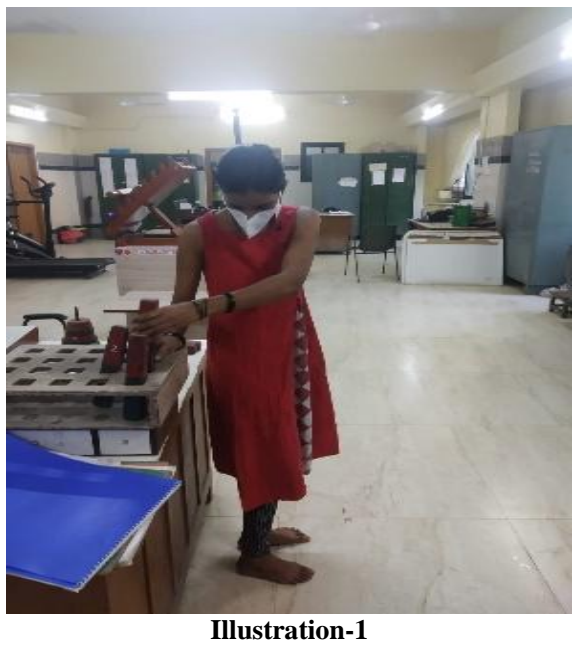

The patient doing trunk rotations to increase her flexibility and reducing truncal rigidity

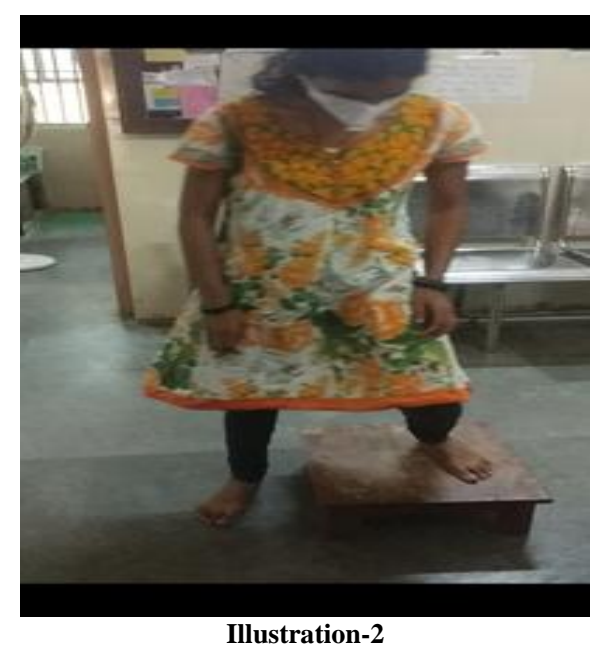

Lateral step-ups to facilitate motor control

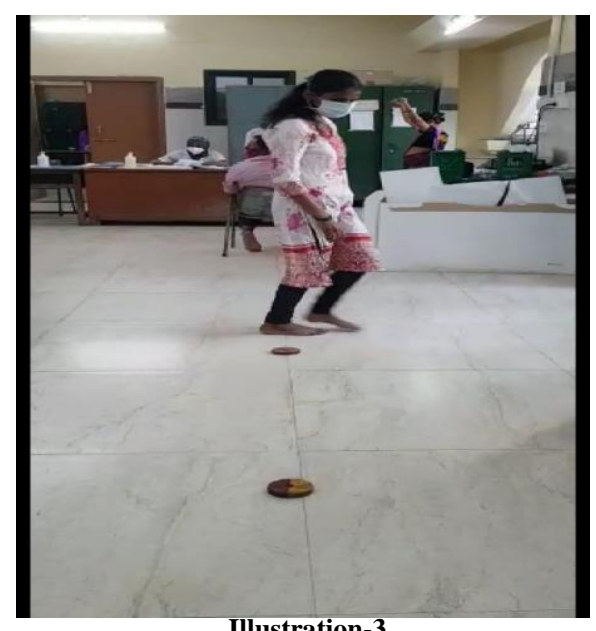

Figure-of-eight walking around obstacles to facilitate obstacle tackling

\section{Follow up and Outcomes}

Mrs. M showed significant improvement in the scores of nified Parkinson's Disease Rating Scale pre and post 3 months of Occupational Therapy intervention.

$\mathrm{Pt}$ was assessed on Unified Parkinson's Disease Rating Scale pre- and post- 3 months of Occupational Therapy intervention $^{3}$. The pre-intervention scores in Non-Motor Aspects of Experiences of Daily Living was 12 and the post-intervention score was 7 , which suggested a decline in the symptoms and affectations. She showed considerable improvement in non motor symptoms like anxiety and fatigue. In Motor Aspects of Experiences of Daily Living, reduced from 18 to 11 which showed remarkable improvement in motor aspects like speech, facial expressions, rigidity, tremors, posture, postural stability and gait which led to greater functional use of her fingers, hands and legs. Also in Motor Examination the scores reduced from 43 to 24 and in motor complications the scores reduced from 8 to 5. [See Figure-1]

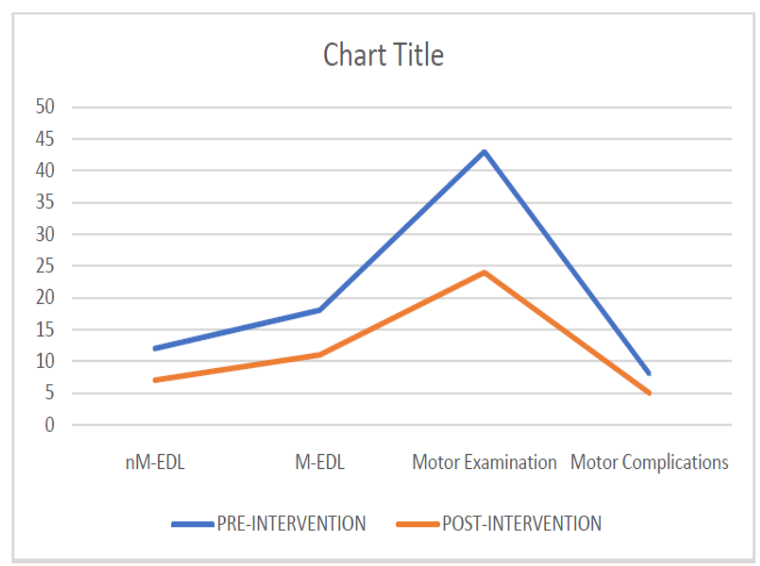

Figure 1

\section{DISCUSSION}

Mrs. $\mathrm{M}$ is suffering from a progressive neurodegenerative disorder, Young Onset Parkinson's Disease. She was assessed on UPDRS pre and post Occupational Therapy Intervention. We used a unique PEO based intervention approach considering the clinical presentation of patient's disease ${ }^{4}$. The 
intervention protocol was individualised considering patient's needs and concerns. It was found that post intervention; patient had reduced anxiety, postural hypotension and fatigue $^{6}$. This change can be attributed to the person based intervention targeted for improvement of performance components.

Post therapy, patient communication difficulties were improved which in turn enhanced her participation in leisure activities (hobbies and other activities).

This can be attributed to the task specific oromotor training done during therapy sessions (activities like reading aloud, practising phonetics, etc).

Her motor skills did not improve remarkably however, she learned to use correct biomechanical techniques for performing motor tasks which is seen as no deterioration in motor scores. It was also observed that with use of precise therapeutic techniques targeted towards modification of patient's environment, occupational needs and personal capacities, off phase duration has been lengthened. Though, the effect of medications cannot be underestimated.

Ellana Welsby et al. concluded in Effectiveness of occupational therapy intervention for people with Parkinson's Disease: Systemic Review (Aust Occup Ther J. 2019) that occupational therapy interventions focussing on meaningful activities were shown to improve perceived occupational performance.

Thus, it can be concluded that a tailor-made Occupational Therapy Intervention using PEO Model has not only brought about positive changes in the motor complaints but also non motor affectations and has helped in improving the quality of life of the patient.

\section{Patient Perspective}

The patient says that she herself can feel the positive changes not only in the strength, flexibility, tremors and other motor affectations but also in the way she communicates verbally and non verbally. She also feels confident now in performing her activities of daily living. She also feels less anxious now.

\section{Informed Consent Statement}

Mrs. $M$ has signed an informed consent letter stating that she is willing to participate in the case study report and that her information will be kept confidential. Also she has no objection in using her pictures for the same.

\section{Abbreviations}

YOPD (Young Onset Parkinson's Disease), MDS-UPDRS (Movement Disorder Society sponsored revision of the Unified Parkinson's Disease Rating Scale), PEO (Person Environment Occupation)

\section{Acknowledgement}

We would like to acknowledge the HOD of our Occupational Therapy Dept for allowing us to conduct the case study.

\section{Conflict of Interest: None}

\section{Source of Funding: None}

\section{Declaration of Patient Consent:}

Appropriate patient consent was taken prior to publication in the journal.

\section{REFERENCES}

1. George DeMaagd, Ashok Philip. Parkinson's Disease and its Management, Part 1: Disease Entity, Risk Factors, Pathophysiology, Clinical Presentation and Diagnosis. P T. 2015 Aug;40(8):504-32.

2. Schrag A, Hovris A, Morley D, Quinn N, Jahanshahi M. Young-versus older-onset Parkinson's disease: impact of disease and psychosocial consequences. Mov Disord. 2003 Nov;18(11):1250-6.

3. Goetz C, Poewe W, Rascol O, Samaio C, Fahn S, Stebbins G, Lang A et al. The Unified Parkinson Disease Rating Scale (UPDRS): Status and Recommendations. Movement Disorders. 2003;18(7):738-750

4. Law M, Cooper B, Strong S. The PersonEnvironment-Occupation Model: A Transactive Approach to Occupational Performance. Canadian Journal of Occupational Therapy. 1996;63(1): 9-23 
5. Prenger, M.T.M.; Madray, R.; Van Hedger, K.; Anello, M.; MacDonald, P.A. Social Symptoms of Parkinson's Disease. Preprints 2020, 2020070602 (doi: 10.20944/ preprints 202007.0604.v1)

6. Seyed- Mohammed Fereshtehnejad, Hasti Hadizadeh, Farhadi, Gholam Ali Shahidi, Ahmad Delbari, Johan Lokk, "Comparison of the psychological symptoms and DiseaseSpecific Quality of life between Early- and Typical- Onset Parkinson's Disease Patients", Parkinson's Disease, vol.2014, Article ID 819620, 7 pages,2014. http://doi.org/10.1155/2014/819620

7. Welsby E, Berrigan S, Laver K. The Effectiveness of Occupational Therapy intervention for people with Parkinson's Disease: Systematic review. Aust Occup Ther J. 2019 Dec;66(6):731-738. doi:10.1111/1440-1630.12615.Epub 2019 Oct 10.PMID:31599467

8. Smania N, Corato E, Tinazzi M, Stanzani C, Fiaschi A, Giardi P, Gandolfi M. Effect of balance training on postural instability in patients with idiopathic Parkinson's disease. Neurorehabil Neural Repair.2010 Nov-
Dec;24(9):826-34.

doi:10.1177/1545968310376057.PMID:

21045119

9. Sturkenboom IH, Graff MJ, Hendriks JC, Veenhuizen Y, Munneke M, Bloem BR, Nijhuis-van der Sanden MW; OTiP study group. Efficacy of occupational therapy for patients with Parkinson's disease: a randomised controlled trial. Lancet Neurol.2014 Jun;13(6):557-66. doi:10/1016/ S1474-4422(14)70055-9. Epub 2014 Apr 8.Erratum in: Lancet Neurol. 2014 Jun;13 (6):536. Erratum in: Lancet Neurol.2016 Mar;15(3):241. PMID: 24726066

10. Curtis, Catherine L, Clare C, Luciene J. Effects of Exercise on the Motor Control of Individuals with Parkinson's Disease, Neurology Report:2001:25(1):2-11

How to cite this article: Sehra Bk, Gokhale P. Effectiveness of occupational therapy intervention in young onset Parkinson's Disease-a case report. International Journal of Science \& Healthcare Research. 2021; 6(3): 173-178. DOI: https://doi.org/10.52403/ijshr. 20210729 